\title{
Osteon interfacial strength and histomorphometry of equine cortical bone
}

\author{
Robert F. Bigley, Lanny V. Griffin*, Lisa Christensen, Ryan Vandenbosch \\ California Polytechnic State University, Department of Materials Engineering, San Luis Obispo, CA 93407, USA
}

\begin{abstract}
The interfacial strength of secondary osteons from the diaphysis of the Thoroughbred equine third metacarpal was evaluated using the fiber pushout test. The pushout was performed on $300-500 \mu \mathrm{m}$ sections of $4 \times 4 \times 15 \mathrm{~mm}$ bone blocks machined from four anatomic regions of the cortex. Pushout strength was evaluated from proximal to distal location within the diaphysis on four osteon types classified under polarized light on adjacent histologic sections from each block. The shear strength of the interfaces were estimated from shear lag theory. Differences were found in the interfacial strength of osteons based on appearance under polarized light with bright field having the highest interfacial strength (40.3 MPa). The lowest strength was found in the dark field osteons $(22.8 \mathrm{MPa})$. The dorsal region had the highest shear strength and toughness compared to all other regions. The cement line and interlamellar interfaces are similar in strength, but exhibit regional dependence - specifically, the palmar region strength is less $(17.5 \mathrm{MPa})$ than the osteon interlamellar interfaces $(30.4 \mathrm{MPa})$ and osteon type dependent (alternating significantly weaker than other types). Histomorphometry revealed significant regional differences $(p<0.0001)$ in osteon area fraction among the four osteon types as well as differences in the osteon diameter $(p=0.01)$, with dorsal regions having larger osteons $(170 \mu \mathrm{m})$ than the palmar region $(151 \mu \mathrm{m})$. Fatigue life and fracture toughness of Haversian bone are reported in the literature to be regionally dependent and are known to be associated with osteon pullout - an osteon interfacial phenomenon. Therefore, the results presented in this study are important to further the understanding of the mechanisms of fragility and damage accumulation in cortical bone.
\end{abstract}

\section{Introduction}

Cortical bone tissue is considered analogous to an engineered fiber reinforced composite material (Guo et al., 1998; Hogan, 1992; Katz et al., 1984). By this analogy, the osteon acts as the fiber with the matrix being interstitial bone and remodeled osteon fragments. Numerous studies on fracture and fatigue processes of cortical bone have demonstrated similarities to those same processes in engineered composite materials (Alto and Pope, 1979; Bell et al., 1999; Gibson et al., 1995;
Guo et al., 1998; Martin et al., 1996a, b; Moyle et al., 1978).

The osteon and its interfaces have been the focus of many studies because of the potential contribution to the fracture and fatigue resistance of bone (Dong and Guo, 2000, 2001; Gibson et al., 1995; Griffin et al., 1997; Guo et al., 1998; Hiller et al., 2003a, b; Hogan, 1992; Katz et al., 1984). Further, osteon pullout has long been recognized as an important phenomena associated with fracture and fatigue of cortical bone (Behiri et al., 1987; Bonfield, 1987; Bonfield and Behiri, 1989; Cooke et al., 1973; Corondan and Haworth, 1986; Hiller et al., 2003a, b; Moyle and Bowden, 1984; Moyle et al., 1978; Piekarski, 1970; Pope and Outwater, 1972).

The osteon is complex, with numerous interfaces and differing structures. Ascenzi and Bonucci classified three 
types of osteons, type L (dark field) with longitudinally oriented collagen, type $\mathrm{T}$ (bright field) with nearly transverse orientation of collagen with respect to the osteon long axis, and type A (alternating) (Ascenzi and Benvenuti, 1986; Ascenzi and Bonucci, 1967; Ascenzi and Bonucci, 1968; Ascenzi and Bonucci, 1976). More recently, Martin et al. characterized a hooped osteon (type O) using circularly polarized light (Martin et al., 1996a, b). Martin and coworkers observed that osteon structure is significantly more complicated, although these simplified groupings are still useful definitions. Recent studies have shown that osteon structural differences may be related to collagen fiber orientation, and are likely to affect bone mechanical performance (Ascenzi et al., 1997; Ascenzi et al., 2003).

Frost and coworkers were the first to investigate the osteon-level shear properties of bone using a simple shear test (Frost et al., 1961). Later, Ascenzi and Bonucci (1972) reported that bright field and alternating osteons had equal shear strengths, while dark field osteons were weakest in shear. In their tests, Ascenzi and Bonucci were never able to obtain failure along a cement line and concluded that the cement line was a strong interface, although later they have accepted that the cement line is likely to be weak or more ductile (Ascenzi et al., 1997). It is likely that the results of Ascenzi and Bonnucci were significantly influenced by the difference in the pushout tool diameter and the receiving hole diameter (Dong and Guo, 2000, 2001).

Dong and Guo $(2000,2001)$ applied pushout techniques, similar to Ascenzi and Bonucci's, to human cortical bone and reported, unlike Ascenzi and Bonucci, that the cement line interface was weaker in shear compared to interlamellar interfaces. The major difference between these investigations was in the punch and receiving hole sizes.

The goal of the present research was to develop a better understanding of the interfacial properties associated with osteons in equine cortical bone. The hypotheses were, first, that interfacial properties will be dependent on the collagen fiber orientation of the osteon because this affects the mechanics of the interface. Secondly, there will be anatomic regional differences in osteon interfacial properties and histomorphometry since local variations in mechanical loading affect bone microstructure. It was further hypothesized that the cement line would be a weaker interface than the osteon interlamellar interface.

\section{Methods}

This study utilized the third metacarpal (cannon bone) from one Thoroughbred racehorse. The bone was kept frozen at $-20^{\circ} \mathrm{C}$ except while machining or testing. Five transverse bone discs, located from proximal to distal, were cut from the diaphysis. The location of the bone disc within the diaphysis, as measured from the proximal articular surface, will be referred to as location for the purposes of this paper. Bone blocks averaging $4 \times 4 \times 15 \mathrm{~mm}$ were cut from each of these discs using a low-speed precision diamond cut-off saw with a $500 \mu \mathrm{m}$ thick wafering blade (Isomet 1000 , Buehler) under constant irrigation of distilled water to minimize heating of the bone. For the bone blocks used in this study, the $15 \mathrm{~mm}$ dimension was aligned with the longitudinal axis of the cannon bone. Four bone blocks were prepared from each of the four anatomical regions: dorsal (D) (analogous with anterior region in human), medial (M), lateral (L), and palmar (P) (analogous to posterior region in human). To maintain a consistent reference, each block was chamfered on one edge along the long axis and a small vnotch was cut into one face prior to sectioning. For the purposes of this study, region refers to the anatomic quadrant. The serial sectioning of a bone block produced nine pushout samples with thicknesses ranging from 300 to $500 \mu \mathrm{m}$, and five $100 \mu \mathrm{m}$ thick sections for osteon pushout type selection and histology (Fig. 2). A range in thicknesses was chosen so that a fitting procedure could be performed using a shear lag model to be described later. The pushout specimens were deburred and polished using 1500 grit sandpaper in a calcium-buffered saline solution. The pushout sections were numbered for each block and the histologic sections were mounted on a glass slide for further analysis.

\subsection{Osteon selection}

Using the $100 \mu \mathrm{m}$ histologic sections, osteons were selected for pushout. The circularity index (CI) was defined as the ratio of the area enclosed by the peripheral boundary of the osteon to the area of a circle with the same perimeter. Thus the value would be 0 for a straight line, and 1 for a circle. The peripheral boundary of the osteon was physically traced using an image analysis program (Bioquant 5.0, Nashville, TN) and the CI was calculated automatically.

Osteons were selected for pushout using five criteria: (1) $\mathrm{CI} \geqslant 0.90$, circular osteon necessary for shear stress calculation; (2) conformity to the polarized light birefringence classification scheme (Fig. 1); (3) definite cement line present (secondary osteon) and refilling of the osteon appeared to be complete; (4) not less than $500 \mu \mathrm{m}$ from a specimen edge to minimize free edge effects; and (5) $200 \pm 10 \mu \mathrm{m}$ in diameter, physically measured using an image analysis program (Bioquant 5.0, Nashville, TN), calculated by averaging the largest and smallest measured diameters. This diameter was used for subsequent data analysis of the shear strength. 

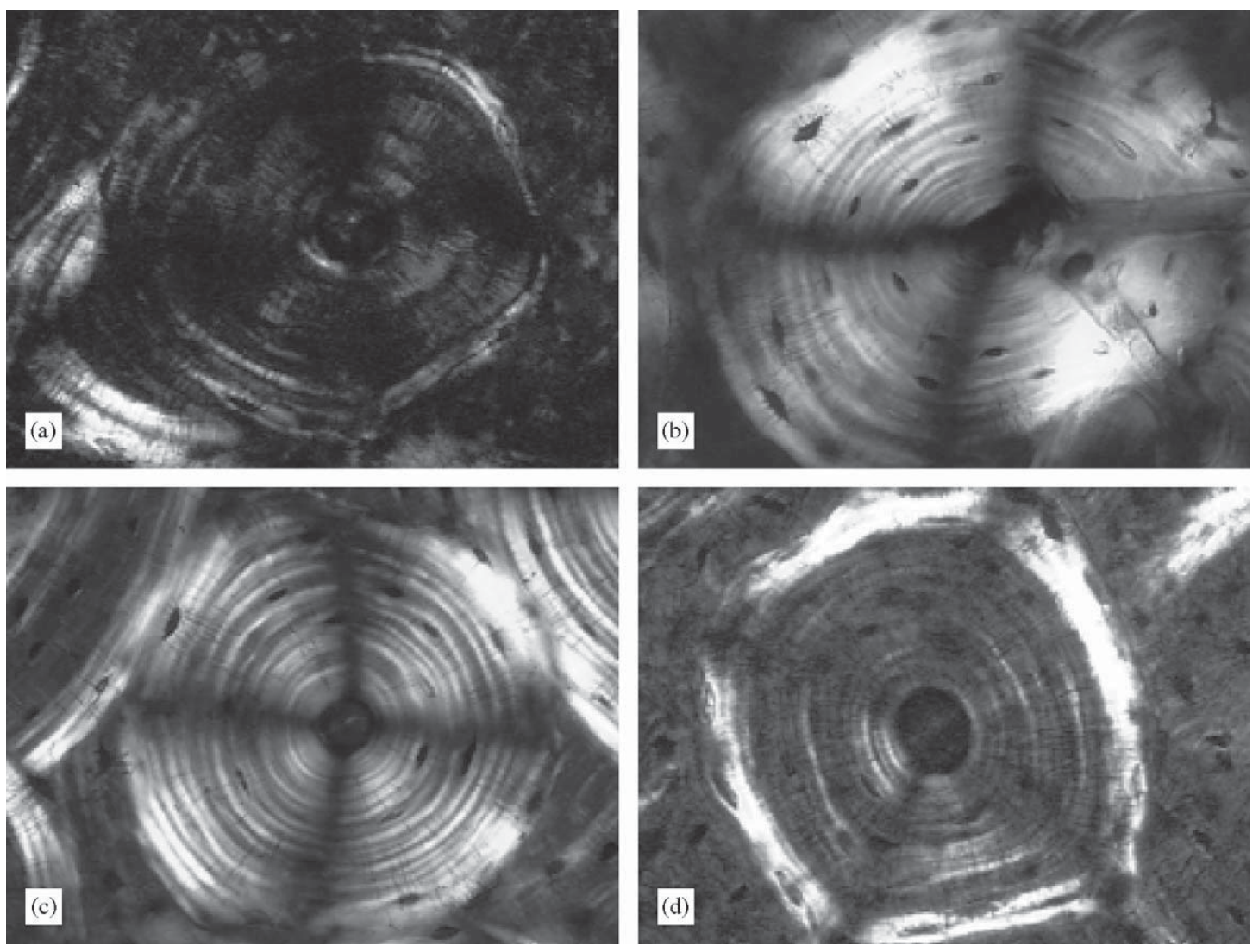

Fig. 1. Classification of osteons based on birefringence at $200 \times$. (a) Dark field (Type L) osteon, (b) bright field (Type T) osteon, (c) alternating (Type A) osteon, (d) hooped (Type O) osteon.

Table 1

Cyclic permutation for disc's from the diaphysis

\begin{tabular}{lllll}
\hline \multirow{5}{*}{ Disc } & \multicolumn{4}{l}{ Block within each disc } \\
\cline { 2 - 5 } & 1 & 2 & 3 & 4 \\
\hline 1 & Bright field & Alternating & Hooped & Dark field \\
$2^{\text {a }}$ & Hooped & Hooped & Hooped & Hooped \\
$3^{\text {b }}$ & Dark field & Bright field & Alternating & Hooped \\
4 & Hooped & Dark field & Bright field & Alternating \\
5 & Alternating & Hooped & Dark field & Bright field \\
\hline
\end{tabular}

${ }^{\text {a } P e r m u t a t i o n ~ w a s ~ d e f i n e d ~ a f t e r ~ o s t e o n s ~ f r o m ~ d i s c ~} 2$ were selected and pushed.

${ }^{\mathrm{b}}$ Histomorphometry data were obtained from disc 3 .

This criterion was necessary to match the diameter of the pushout tool to the osteon and receiving hole.

Each block within a region $(\mathrm{D}, \mathrm{M}, \mathrm{L}, \mathrm{P})$ was numbered 1-4 for a total of 16 blocks per disc. For all sections with each bone block, one type of osteon was selected. To the extent possible, osteon types were selected for each disc using a cyclic permutation shown in Table 1 to minimize biases of osteon selection. In the event that an osteon meeting the selection criterion of the permutated type was not present within the specified block, an available type that would supplement deficiencies in data for the region was selected (Fig. 2).

\subsection{Pushout and evaluation}

The $x-y$ coordinates of the selected osteon were recorded for the histologic section closest to the pushout section to be tested using an image analysis program (Bioquant 5.0, Nashville, TN). The osteon was then located on the test section using an $x-y$ measuring stage with high-resolution digital micrometers (Digimatic, Mitutoyo, Tokyo, Japan) and manually marked with a cell marker.

A pushout sample tray with twelve $300 \mu \mathrm{m}$ holes was placed on the measuring stage of a reflected light metallographic microscope (Olympus BX-30, Tokyo, Japan). The hole was located in the cross-hair reticle and the osteon was then positioned over the hole. Up to nine sections from a complete bone block series were positioned on the tray. Pushout was conducted at room temperature $\left(21^{\circ} \mathrm{C}\right)$ using a cylindrical tungsten carbide probe tip $($ diameter $=187 \mu \mathrm{m})$ at a constant displacement rate $(1.0 \mu \mathrm{m} / \mathrm{sec})$ using a custom pushout device (Microtest 600, Micromaterials, UK). Specimens were kept moist with calcium-buffered, $0.9 \%$ saline solution 


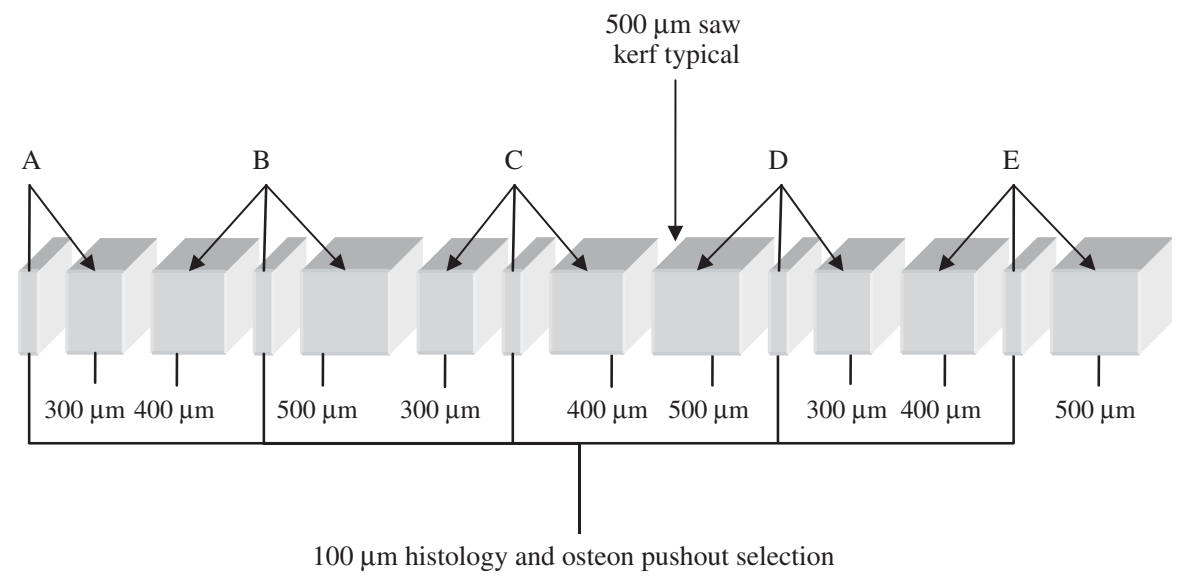

Fig. 2. Sectioning sequence procedure for transverse bone sections. The entire sequence represents a single bone block. Osteon selection was performed using the adjacent $100 \mu \mathrm{m}$ sections: for example, A would be used to select an osteon for the $300 \mu \mathrm{m}$ section; whereas $\mathrm{C}$ would be used to select for the adjacent 300 and $400 \mu \mathrm{m}$ sections, as indicated by the arrows. Drawing is not to scale.

(Gustafson et al., 1996). The acquisition and control software collected force-displacement data for each test.

\subsection{SEM and classification of pushout}

Subsequent to pushout, the samples were prepared for scanning electron microscopy (SEM). Briefly, the specimen was dried in ethanol for $24 \mathrm{~h}$, mounted on an SEM stub, sputter coated with gold, and observed in a field emission SEM at $10 \mathrm{kV}$ (S800, Hitachi, Tokyo, Japan). Pushout results were classified into five categories under SEM: (0) no pushout, (1) interstitial bone shear-out, (2) fragment, partial, or branched pushout, (3) interlamellar osteon pushout, and (4) cement-line fracture (Fig. 3). An interlamellar fracture was differentiated from a cement line fracture by several methods: (1) the size of the osteon, (2) concentric osteonal lamellae present beyond pushed out osteon, and (3) appearance of the fracture surface. In addition to pushout score, the collagen fiber angle on the fracture surface was measured between $0^{\circ}$ and $90^{\circ}$, where $0^{\circ}$ was oriented along the osteon long axis.

\subsection{Data analysis}

Numerous theoretical and experimental analyses of the fiber pushout problem have been reported in the composites literature. The typical pushout test load displacement curve performed under displacement control exhibits four distinct regions (Fig. 4). The first is a linear region, functionally related to the material elastic properties and indenter geometry. The second region begins with a departure from linearity of the force-displacement curve related to debonding of the interface (initiation of a mode II crack), inelastic deformation of the material, or combination of both. The third region begins at the maximum load at which point the critical length crack propagates catastrophically until the osteon fully debonds and is manifested in the load curve by a rapid load loss. The fourth region begins when the load curve levels off and slowly drops corresponding to frictional sliding of the osteon against the interface (Fig. 4). This delineation is somewhat ambiguous, but the greatest value was chosen that occurred in this nearly linear region. Debonding of the osteon was assumed to occur at the departure from linearity in the force-displacement, fixing a value for the debonding load $\left(P_{\mathrm{d}}\right)$. The debonding load was automatically calculated (Matlab 6.0, The Mathworks, Waterloo, MI) using a linear offset method by first fitting a line through the linear portion of the load displacement curve, then offsetting the line by $2 \mu \mathrm{m}$, calculating the intercept of the line with the load displacement curve (Fig. 4). The offset ensures consistency in the definition of the debond load and is analogous to the definition of yield strength by offset in plastically deforming materials.

Using shear lag theory (Bright et al., 1989), and assuming that the shear strength of the interface is constant, Bright and coworkers showed that an approximate theory of elasticity solution can be obtained for the fully bonded case using the $P_{\mathrm{d}}$ obtained from the pushout trace as

$P_{\mathrm{d}}=\frac{\pi d_{\mathrm{o}} \tau_{\mathrm{d}}}{\beta} \tanh (\beta T)$.

Here, $d_{\mathrm{o}}$ is the osteon diameter, $\tau_{\mathrm{d}}$ is the debonding shear strength of the interface, and $\beta$ is the shear lag parameter and $T$ is the thickness of the section. Eq. (1) provides a better estimate of the actual shear stress distribution along the length of the osteon than simply assuming a constant shear stress. The shear lag parameter is a complicated function of many factors, such as elastic moduli, Poisson's ratio, and volume fraction of fibers, derived using differing assumptions 

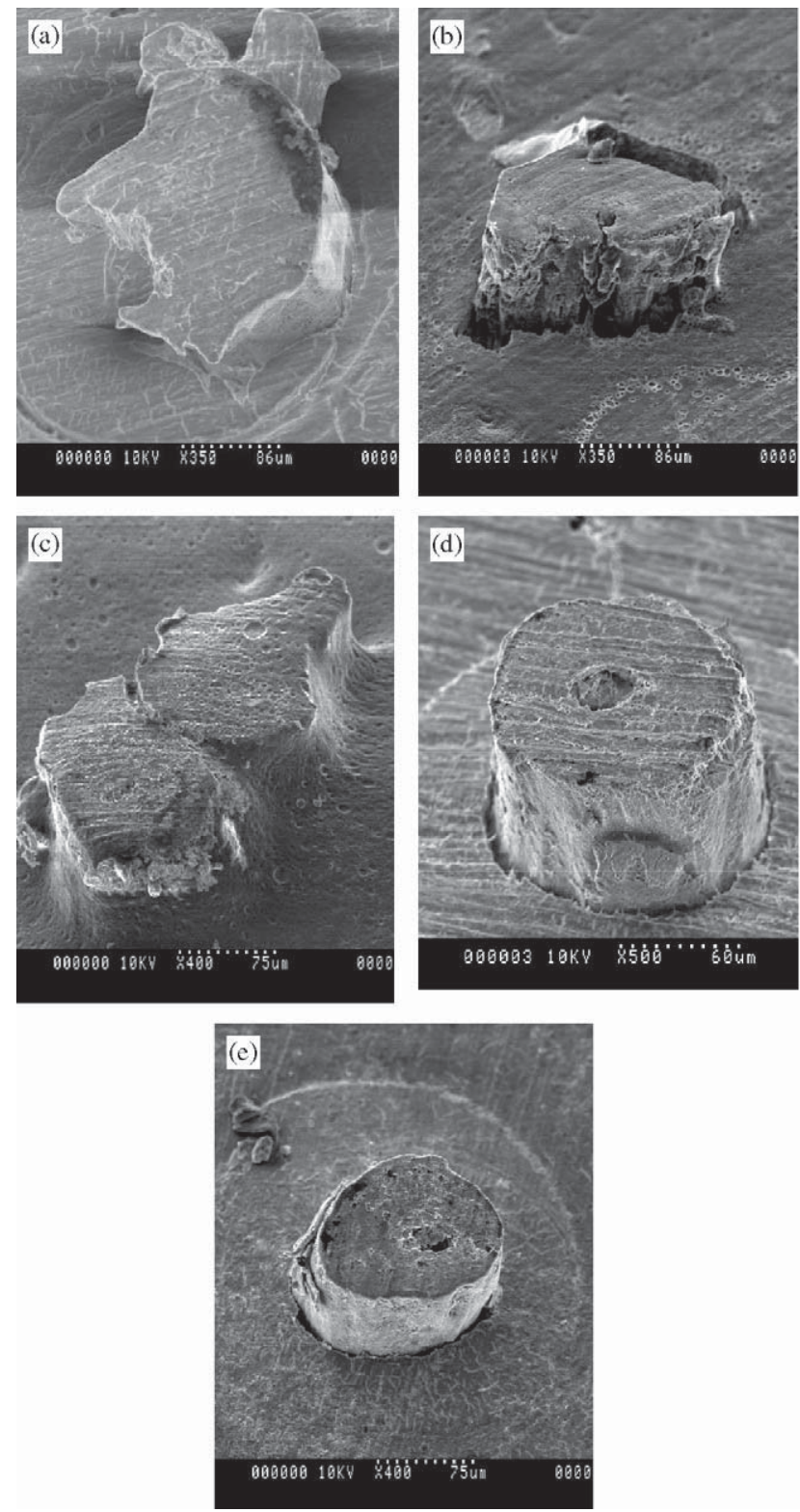

Fig. 3. The classification scheme for various osteons that were pushed out (score 0 not shown). (a) Shear of bone without a visible osteon present (pushout score 1). The rounded edge is a result of shearing on the receiving hole. (b) A fragment of an osteon (pushout score 2), (c) a branched osteon (pushout score 2), (d) an osteon interlamellar shear failure (pushout score 3), (e) an osteon cement line fracture (pushout score 4).

(Lawrence, 1972; Wells and Beaumont, 1985). For the case of bone, the material properties for the osteon or surrounding bone tissue are not known and are related to the degree of mineralization of the tissue. However, Bright and coworkers devised a method for determining the interfacial strength for an unknown shear lag parameter, $\beta$, using a non-linear regression analysis, which involved pushing out embedded fibers of differing lengths in a composite matrix (Bright et al., 1989). They validated the method by comparing regression analyses

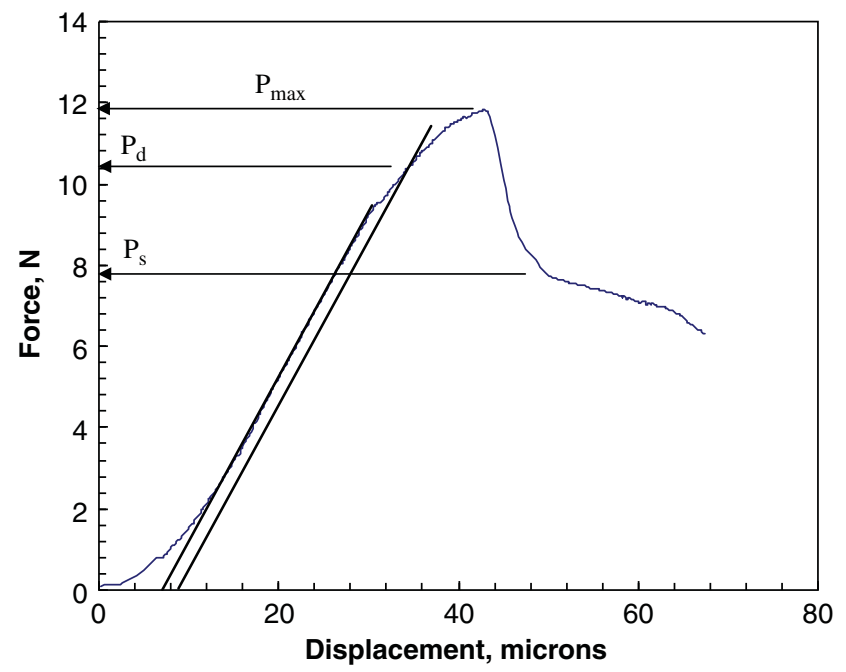

Fig. 4. Typical pushout load displacement curve with the definitions of debonding load $\left(P_{\mathrm{d}}\right)$ based on the $2 \mu \mathrm{m}$ offset, maximum load $\left(P_{\max }\right)$, and frictional sliding load $\left(P_{\mathrm{s}}\right)$.

to calculated values of various ceramic matrix composites. Using the same two-parameter non-linear regression technique, the data for the serial sections were fit to Eq. (1) to estimate the shear strength and shear lag parameter.

The maximum interfacial shear stress is a parameter previously defined in the literature associated with osteon pushout (Ascenzi and Bonucci, 1972; Dong and Guo, 2000; Frost et al., 1961). Using the maximum force $\left(P_{\max }\right)$ from the force-displacement curve, the maximum interfacial shear stress was defined as

$\tau_{\max }=\frac{P_{\max }}{\pi d_{\mathrm{o}} T}$,

where $P_{\max }$ is the maximum load (Fig. 4), $d_{\mathrm{o}}$ is the osteon diameter, and $T$ is the thickness of the section, which is assumed to be the embedded length of osteon.

To evaluate the frictional sliding portion of the osteon pushout force-displacement curve, the frictional sliding shear stress was defined using a constant shear stress assumption

$\tau_{\mathrm{s}}=\frac{P_{\mathrm{s}}}{\pi d_{\mathrm{o}} T}$.

Here, $\tau_{\mathrm{s}}$ is the frictional shear stress, and $P_{\mathrm{s}}$ is the sliding load (Fig. 4), with $d_{\mathrm{o}}$ and $T$ as defined previously.

\subsection{Histomorphometry}

A fraction $(N=80,400$ fields $)$ of the $100 \mu \mathrm{m}$ sections were examined using a linear polarized light microscope (Olympus BX 50, Tokyo, Japan) equipped with an analog camera $(10 \times$ objective lens $)$ to determine the birefringence pattern of the osteon (Fig. 1). At this magnification, it took roughly 16 fields to completely 
cover the section. For typing purposes, the strict grouping of Ascenzi and Bonucci was relaxed somewhat. For this study, to be considered a bright field osteon, all lamella must appear bright, with no interspersed dark lamellae. A dark field osteon was one that exhibited all dark lamellae or a thick bright ring around the Haversian canal. An alternating osteon was defined as having at least two successive alternating pair of lamellae away from the peripheral boundary (hooped) or around the Haversian canal. A hooped osteon had a thick portion of the peripheral boundary with a bright appearance under polarized light.

Histologic data were collected for five of the 16 fields using an image analysis program (Bioquant 5.0, Nashville, TN). Two fields per section were endosteal, two fields were periosteal, and one field was central. The peripheral boundary was physically traced for every type of osteon within a field for each of the five fields. The image analysis program then recorded the area of the osteon. Three parameters were defined for histomorphometric analysis:

Osteon diameter $($ On.Dm $)=2 \sqrt{\frac{\text { Osteon area }}{\pi}}$,

Osteonal area (On.Ar)

$=\frac{\text { Total osteon area including Haversian canal }}{\text { Selected field area }} \times 100$,

Porosity $=\frac{\text { Total pore area }}{\text { Selected field area }} \times 100$.

Osteon diameter (On.Dm), as a histomorphologic measure, was determined in the image analysis program as the area enclosed by the peripheral boundary of the osteon (Osteon area), and then by assuming the area enclosed was a circle, the diameter was estimated using the area of a circle formula (Eq. (4)).

Porosity was defined as the Haversian or Volkmann canal spaces (Eq. (6)). The parameters given in Eqs. (4)-(6) were automatically calculated by the image analysis program for each osteon type in 400 fields (four regions, four blocks per region, five sections per block, five fields per section) of the mid-diaphyseal disc (disc 3).

\subsection{Statistical analysis}

A two-way ANOVA (Sigmastat, SPSS, Chigaco IL), with interfacial debond shear strength, maximum interfacial shear stress, or interfacial frictional sliding stress as the continuous response variable and anatomic region, proximodistal location, osteon type, and fracture mode as the factors. Statistics were performed on pushed out osteons with a failure mode score of 3 or 4 because failure occurred along a well-defined interface.
A two-way ANOVA was used to determine significance for the histomorphometry data. In this procedure, area fraction (On.Ar), or diameter (On.Dm) was the response variable, while region, type, and their interaction served as the factors. Fisher's LSD post hoc tests were performed for all of the ANOVA results and statistical significance was reported for $p<0.05$.

Linear regression analyses were performed to determine the histomorphometric effect on debonding, maximum, and frictional sliding stresses of osteons (SAS v8, Cary, NC). For the linear regression models, a combination of forward and backward step analysis procedure was used to determine the best fitting model, with the dependent variable being debond, maximum, or sliding friction shear stress and independent variables were region, osteon type, On.Dm, On.Ar, collagen angle, and porosity.

\section{Results}

In this study 496 osteons were prepared and pushed out. Those scoring 3 (interlamellar fracture) or 4 (cement line fracture) were 120 and the ratio of scores 3 to 4 is $82.3 \%$. Table 2 shows ANOVA results for the pushout tests.

\subsection{Interfacial debonding shear strength}

The interfacial debond shear strength of the cement line interface $(30.7 \pm 3.9 \mathrm{MPa})$ is not significantly different from the interlamellar interface $(32.7 \pm 1.6 \mathrm{MPa})$. Significant differences existed between osteon type and region. For the palmar region, the cement line was weaker (17.5 MPa) than the interlamellar interface $(30.4 \mathrm{MPa}$, $p=0.034)$. The cement line of the alternating osteon is weaker $(12.4 \mathrm{MPa})$ than the interlamellar interface (33.3 MPa, $p=0.0387$ ), whereas the cement line is stronger for the brightfield osteon $(47.1 \mathrm{MPa})$ than the interlamellar interface (33.4 MPa, $p=0.0379)$. The interfacial debond shear strength of osteons from the dorsal region was greater than that of osteons in the medial and palmar regions $(p=0.01)$ but not the lateral region. The bright field osteon types had the highest interfacial debond shear strength $(p=0.003)$. There were also significant differences in the interfacial debond shear strength depending on the proximodistal location within the diaphysis, with the shear strength of osteons from the proximal diaphysis being greater than that of osteons from either the mid or distal diaphysis $(p<0.0001)$.

\subsection{Maximum interfacial shear stress}

The maximum interfacial shear stress of the cement line interface $(70.0 \pm 3.3 \mathrm{MPa})$ was not quite different from the interlamellar interface $(76.7 \pm 1.6 \mathrm{MPa}$, 
Table 2

Summary of the main effects on average interfacial shear strength and toughness

\begin{tabular}{llll}
\hline Effect & $\begin{array}{l}\text { Maximum } \\
\text { interfacial }\end{array}$ & $\begin{array}{l}\text { Interfacial } \\
\text { debond shear }\end{array}$ & $\begin{array}{l}\text { Frictional } \\
\text { sliding stress }\end{array}$ \\
& shear stress & strength & $(\mathrm{MPa})$ \\
$(\mathrm{MPa})$ & $(\mathrm{MPa})$ & \\
\hline
\end{tabular}

Disc and location

from proximal

plateau $(\mathrm{cm})$

(1) 10.9

(2) 12.7

(3) 14.7

(4) 16.6

(5) 20.3

Region

Dorsal

Lateral

Medial

Palmar

Osteon type

Alternating

Bright field

Dark field

Hooped

Failure mode

Cement line

Interlamellar

$79.0 \pm 6.4^{\mathrm{a}}$
$67.0 \pm 2.7^{\mathrm{b}}$
$72.9 \pm 3.5^{\mathrm{a}, \mathrm{b}}$
$77.5 \pm 2.4^{\mathrm{a}}$
$70.4 \pm 2.5^{\mathrm{a}, \mathrm{b}}$

$45.1 \pm 3.3^{\mathrm{a}}$

$37.7 \pm 2.1^{b}$

$24.1 \pm 2.5^{\mathrm{c}}$

$25.9 \pm 3.5^{\mathrm{c}}$

$25.5 \pm 7.7^{\mathrm{b}, \mathrm{c}}$

$37.9+2.8^{\mathrm{a}}$

$49.6 \pm 3.0^{\mathrm{a}}$

$48.2 \pm 3.0^{\mathrm{a}}$

$46.2 \pm 2.9^{\mathrm{a}}$

$46.5 \pm 2.8^{\mathrm{a}}$

$47.2 \pm 4.2^{\mathrm{a}, \mathrm{b}}$

$46.4 \pm 3.9^{\mathrm{a}, \mathrm{b}}$

$49.8 \pm 3.6^{\mathrm{a}}$

$39.2 \pm 3.9^{b}$

$26.8 \pm 2.7^{\mathrm{b}, \mathrm{c}}$

$24.0 \pm 2.4^{\mathrm{c}}$

$48.4 \pm 2.8^{\mathrm{a}}$

$44.7 \pm 3.7^{\text {a.b }}$

$36.1 \pm 3.6^{b}$

$53.4 \pm 1.1^{\mathrm{a}}$

$63.6 \pm 4.2^{b}$

$71.0 \pm 2.0^{\mathrm{c}}$

$40.3+3.5$

$32.1 \pm 4.0^{\mathrm{a}, \mathrm{b}}$

$31.4 \pm 2.3^{\mathrm{a}}$

$43.1 \pm 1.6^{\mathrm{a}}$

$70.0 \pm 3.3^{\mathrm{a}^{*}}$

$30.7 \pm 3.9^{\mathrm{a}}$

$32.7 \pm 1.6^{\mathrm{a}}$
$48.3 \pm 2.9^{\mathrm{a}}$

Values are reported as mean \pm standard error. Results based on a sample of $N=120$ osteons. Different alphabetical superscripts within a column for the same effect are the results of post hoc tests and indicate statistically significant differences $(p<0.05)$. The diaphyseal location is reported sequentially from proximal (1) to distal (5). For the failure mode of the maximum interfacial shear strength, the superscript * denotes nearly significant $(p=0.0514)$.

$p=0.0514)$. There were no significant interactions detected between the failure mode (interlamellar or cement line) and osteon type, region, or location. The maximum interfacial shear stress of osteons from the dorsal region was greater than that of osteons in either the medial, lateral, and palmar regions $(p=0.01)$. The bright field and alternating osteon types had a greater maximum interfacial shear stress than the dark field and hooped types $(p=0.003)$, for which the trend was somewhat different from the debond shear strength. There were also significant differences in the maximum interfacial shear stress depending on the proximodistal location within the diaphysis, with the shear stress of osteons from the most proximal diaphysis being generally greater than that of osteons from either the mid or distal diaphysis $(p<0.0001)$.

\subsection{Frictional sliding shear stress}

There are no differences in the frictional sliding stress associated with the cement line interface or the

Table 3

Summary of the main effects on osteon area fraction and average diameter (mean $\pm \mathrm{SD}$ ). Complete histomorphometric data were taken from the mid-diaphyseal disc only

\begin{tabular}{lcl}
\hline Main effect & On.Ar $(\%)$ & On.Dm $(\mu \mathrm{m})$ \\
\hline Anatomical region & $(p=0.7332)$ & $(p=0.0133)$ \\
Dorsal & $53.78 \pm 0.0934^{\mathrm{a}}$ & $170.16 \pm 25.05^{\mathrm{a}}$ \\
Lateral & $54.63 \pm 0.0560^{\mathrm{a}}$ & $164.91 \pm 17.21^{\mathrm{a}}$ \\
Medial & $48.80 \pm 0.0295^{\mathrm{a}}$ & $161.89 \pm 23.44^{\mathrm{a}}$ \\
Palmar & $45.11 \pm 0.0713^{\mathrm{a}}$ & $150.98 \pm 9.99^{\mathrm{b}}$ \\
Osteon type & $(p<0.0001)^{\mathrm{a}}$ & $(p<0.0001)$ \\
Bright field & $5.83 \pm 5.68^{\mathrm{a}}$ & $142.51 \pm 17.99^{\mathrm{a}}$ \\
Dark field & $17.94 \pm 11.22^{\mathrm{b}}$ & $167.72 \pm 19.10^{\mathrm{b}}$ \\
Alternating & $8.85 \pm 6.45^{\mathrm{a}}$ & $169.29 \pm 15.88^{\mathrm{b}}$ \\
Hooped & $17.96 \pm 9.24^{\mathrm{b}}$ & $168.42 \pm 17.36^{\mathrm{b}}$ \\
\hline
\end{tabular}

Values that share the same superscript letter are not significantly different statistically $(p>0.05)$.

interlamellar interfaces. The frictional sliding shear stress of osteons from the medial region was greater than that of osteons in the palmar regions $(p=0.01)$ but not the lateral or dorsal regions. The hooped osteon types had the highest frictional sliding stress compared to the dark field $(p=0.003)$, but not significantly different from the alternating or bright field osteon type.

\subsection{Histomorphometric evaluations}

The average value of total remodeled On.Ar is $50.58 \pm 7.18$ (Table 3 ). The interaction between anatomical region and osteon type for On.Ar proved to be statistically significant $(p=0.0002)$. The On.Ar of particular osteon types was not uniformly distributed throughout each region (Table 3 and Fig. 5). While there were significant regional differences in On.Dm, as well as differences in On.Dm for various types of osteons, there was not a significant interaction for On.Dm between region and osteon type.

\subsection{Influence of histomorphometry on interfacial stress}

Neither region nor osteon type affected debond strength of an osteon when histomorphometry is considered, although it is significantly affected by the surrounding tissue. Regression model coefficients for predicting interfacial debond shear strength from surrounding histomorphometric parameters are given in Table 4.

The frictional sliding shear stress was also significantly affected by the surrounding tissue (Table 6). For the frictional sliding shear stress, all histomorphometric measures, except those that describe the hooped osteon, are important. Additionally, the type of osteon affected the frictional sliding shear stress, as well as whether or not a cement line fracture was present. Here the 


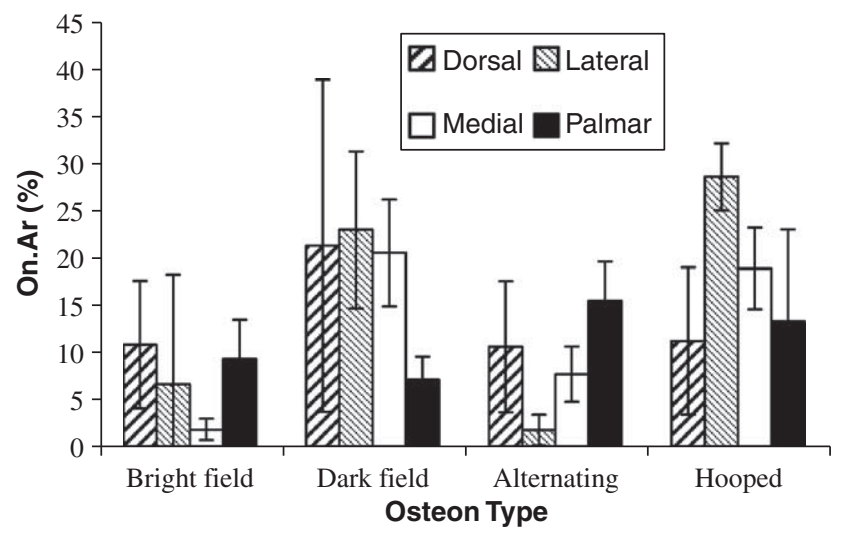

Fig. 5. Interaction of anatomical region crossed with osteon type for average osteonal volume fraction.

Table 4

Regression model for predicting interfacial debond shear strength from histomorphometric parameters $\left(R^{2}=0.92\right)$

\begin{tabular}{lccr}
\hline Variable & Parameter estimate & Standard error & $p$ Value \\
\hline Intercept & -340.40 & 43.84 & $<0.0001$ \\
Hoop.On.Ar & 186.22 & 16.97 & 0.0001 \\
Bright.On.Ar & 820.83 & 106.82 & $<0.0001$ \\
Dark.On.Ar & 116.38 & 25.40 & 0.0018 \\
Alt.On.Ar & -47.48 & 23.04 & 0.0733 \\
Hoop.On.Dm & 0.54 & 0.23 & 0.0442 \\
Bright.On.Dm & -0.33 & 0.09 & 0.0079 \\
Dark.On.Dm & 0.93 & 0.16 & 0.0004 \\
Alt.On.Dm & -2.15 & 0.44 & 0.0001 \\
Porosity & 711.24 & 123.09 & 0.0004 \\
Failure mode & -4.05 & 2.08 & 0.0883 \\
Collagen orientation & -0.09 & 0.04 & 0.0503 \\
\hline
\end{tabular}

frictional sliding shear stress of the interlamellar interface was greater than that of the cement line.

Collagen fiber orientation was not a good predictor for frictional shear stress as was the case for the debond strength. Further, the maximum interfacial shear stress was not able to be predicted by any combination of histomorphometric parameters (Table 5).

SEM analysis revealed trends in the interlamellar failures of pushed out osteons. Fig. 6 shows a region of the interlamellar interface that demonstrated transverse collagen linkages and crystallite debonding.

\section{Discussion}

The hypotheses that interfacial properties would be dependent on the collagen fiber orientation of the osteon was confirmed, as well as demonstrating anatomic regional differences in osteon interfacial properties and histomorphometry. Furthermore, the cement line appears to be weaker than the osteon interlamellar
Table 5

Best fitting regression model for predicting maximum interfacial shear stress from histomorphometric parameters $\left(R^{2}=0.05\right)$

\begin{tabular}{lclr}
\hline Variable & Parameter estimate & Standard error & $p$ Value \\
\hline Intercept & 85.29 & 8.80 & $<0.0001$ \\
Bright.On.Ar & -0.90 & 0.67 & 0.1950 \\
Dark.On.Dm & -0.81 & 0.47 & 0.0998
\end{tabular}

Histomorphometry does not explain maximum interfacial shear stress.

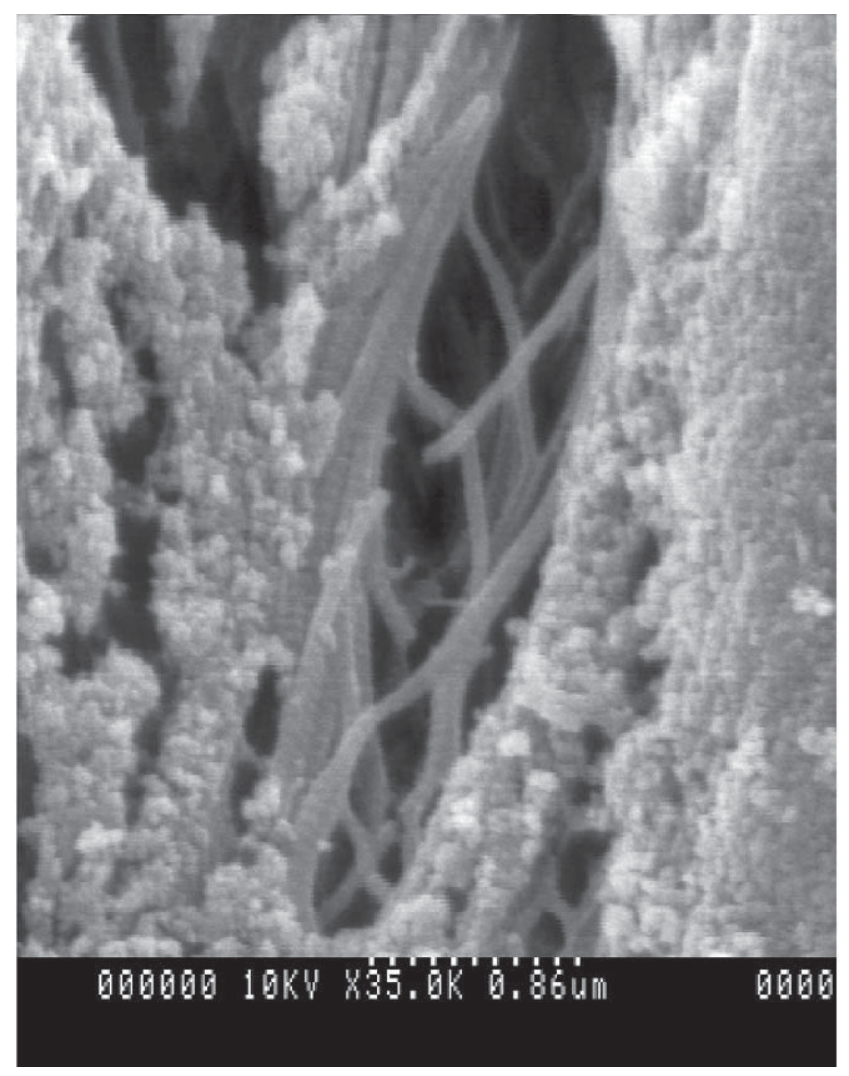

Fig. 6. SEM photomicrograph showing the presence of collagen and crystallite debonding in the interlamellar fracture site in an interior lamellae.

interface, but is regionally dependent and depends on the osteon type.

Collagen fiber orientation of the peripheral boundary of the osteon was found to be a predictor of interfacial debond shear strength (Table 4). As the collagen orientation became more longitudinal, the debond strength was observed to decrease. If birefringence in equine osteons is related to collagen fiber orientation as in human osteons, as Ascenzi and Bonucci have put forward (Ascenzi and Benvenuti, 1986; Ascenzi and Bonucci, 1967), then the interfacial debond strength of the dark field osteon should be less than the bright field osteon. The ANOVA results concur with this observation. While there may be structural differences between 
equine osteons and human osteons which may affect birefringence, collagen orientation-at least at the peripheral boundary - appears to be important.

More importantly, if interfacial debonding is indeed related to collagen fiber orientation, fracture and fatigue processes should be influenced as well. Thus, regions with many longitudinally oriented osteons, such as the dorsal region (Table 3, Fig. 5), would be more likely to have osteon pullout under fatigue or fracture loading. Osteon pullout is positively correlated with fatigue life and occurs mostly in the dorsal region of equine bone (Hiller et al., 2003a, b; Stover et al., 1995). Further, debonding along an interface would enhance fracture toughness by energy dissipative processes (Malik et al., 2003; Norman et al., 1996, 1998; Norman and Wang, 1997; Yeni and Fyhrie, 2002). Further detailed studies of equine osteon morphology should address these issues.

The local histomorphometry of the surrounding matrix profoundly influences the shear strength of osteons, as hypothesized (Tables 4, 6). For debond strength, as the fractions of bright field, dark field, and hooped osteons increased, the debond shear strength tends to increase, whereas when alternating osteons increase, the shear strength decreases. As for diameter, when the diameter of bright field and alternating osteons increases, the strength of the osteon decreases. However, when the dark field and hooped diameter increases, the debond strength goes down. At a more macroscopic level, this may suggest that a bright field osteon in a region with large area fractions of both alternating and dark field osteons may exhibit significantly lower debond shear strengths than would typically be expected, suggesting an interaction between region and debond strength. The histomorphometry data (Table 3, Fig. 5) confirms that the dorsal region, which has mostly dark osteons and a balance of the other types, and the largest overall diameter, has the highest interfacial shear strength (Table 2). The palmar region has the fewest dark field osteons and the greatest area fraction of alternating osteons as well as possessing the smallest diameter osteons, and it has the lowest overall debond shear strength.

The pushout strength of an osteon depends not only on the type of osteon but the surrounding matrix as well. Because there are regional differences in the distribution of osteons, there are regional differences in shear strength of interfaces. Indeed, there are also regional differences in elastic properties of the equine third metacarpus, which are related to the degree of mineralization (Gibson et al., 1995; Les et al., 1994; Les et al., 1997). While the degree of mineralization was not explicitly measured, it has been implicitly accounted in the calculation of the debond shear stress through the fitting procedure of Eq. (1) since the shear lag parameter is a function of elastic modulus, Poisson's ratio which are known to be related to degree of mineralization as well other parameters.
The pushout success rate was about $30 \%$. This makes data analysis difficult because of imbalance in the design and affects the power of the results. A possible explanation for the success rate is that the interfaces of osteons are strong. However, several alternative explanations may be argued. For the case where there was no observable osteon pushout (case 0 or case 1, Fig. 3), the osteon likely terminated within the section. There could be sample alignment error, which could produce a fragment or an osteon branched from one into two or more within the section. There was simply no way to tell with certainty whether an osteon is single and complete throughout the section a priori by the methods described. It may be possible to increase the success rate if one had access to a microCT machine with a spacial resolution great enough to image the Haversian system.

The ANOVA showed similar trends between maximum shear strength and debond stress; however, there was no correlation of maximum shear stress with the regional histomorphometry by linear regression as there was with the debond stress. Strictly speaking, the debond strength represented by Eq. (1) is only valid for a fully bonded case, thus involving one process. The maximum interfacial stress is a convolution of at least two additional processes: inelastic deformation and crack propagation. Both may be affected by thickness of the sample or histomorphometry in some coupled fashion, and so it seems possible that histomorphometric differences cannot be found because of an inadequate mathematical model to describe the process. Also, the maximum interfacial stress is found by assuming constant shear stress, which is a poor assumption. The use of the more complicated Eq. (1) appears to be justified for the aforementioned reasons. Further, using Eq. (1) approximates the actual material strength of the interface.

The assumption of uniform stress for the case of frictional shear stress did show significant correlation with histomorphometry, unlike the maximum shear stress. Clearly, this assumption is poor, but it may work for this case by assuming frictional sliding process is dominated by one process, rather than multiple processes seen in the case of maximum stress. Thus, while the mathematical model is inadequate, it may reveal a meaningful trend despite its weakness.

A weakness with the methodology is that it is not possible to resolve exactly when debonding occurs. It was assumed that the debond crack initiates when the departure from linearity occurs. It is likely that some inelastic deformation occurs at the same point of nonlinearity; however, Ascenzi and Bonucci (1976) found that inelastic deformation occurred in tensile loading of osteons when separation of lamellae (rupture of transverse lamellae) occurred. For this study, the loading was dominated by compression and shear. 
Under these conditions, the longitudinally oriented fibers in the lamellae would more likely buckle, leading to microcracking in longitudinally oriented fibers or a weak interface. Thus, if compressive stresses are high enough to cause inelastic deformation of the material, it is highly likely that debonding due to high shear stress along an interface in the osteon will occur simultaneously. Therefore, it seems reasonable to assume that debonding of the osteon occurs when the load displacement curve departs from linearity.

A limitation of this study is that the osteon diameter in all regions was uniform. This was done purposefully in order to limit the number of variables in the statistical analysis, and in the end, appears to be a good choice. With the number of missing data due to unsuccessful pushouts, adding another factor may have rendered statistical analysis intractable. It is certainly possible that osteon interfacial debond strength is dependent on the diameter of the osteon itself. This could result from a varied osteonal structure, the number of lamellae making up the osteon, the degree of mineralization, or a combination of all these factors. Osteon structure has been modeled in a detailed form, and it has been predicted that Poisson's ratio is affected (Braidotti et al., 1995). If Poisson's ratio of the osteon is related to structure (implicitly the osteon type) then the forces necessary to cause debonding, frictional sliding or other phenomena associated with the interface may be altered.

Another significant weakness is that the conclusions of this study are based on observations from only one animal. However, a large number of osteons were sampled, which affords some confidence that at least for this animal, the results are meaningful. Further, the results show similar trends to the data of Ascenzi and Bonucci (1972). Although there are mechanical property differences between human and equine cortical bone, such as fracture toughness and elastic modulus, if one argues the structural similarity between osteons related to collagen fiber orientation, lamellar thickness and so forth, then it would be reasonable to assume that the trends - but not the magnitudes - would be similar.

The cement line has been reported as a thin, collagen fiber deficient interface that was found to be less mineralized than the surrounding bone matrix (Burr et al., 1988). Except for the alternating osteon type and osteons in the palmar region, there were no differences in the strength of the interfaces. The cement line of the bright osteon type appears to be stronger than the interlamellar interface. This may be associated with the buckling of longitudinally oriented collagen fiber and would be consistent with compressive failure of longitudinally oriented fibrous composite materials. In fracture studies of bone where osteon pullout has been demonstrated, the osteon failure occurs along several concentric interlamellar interfaces rather than simply the cement line (Bonfield, 1987; Hiller et al., 2003a, b).
Table 6

Best fitting regression model predicting interfacial frictional sliding shear stress from histomorphometric parameters $\left(R^{2}=0.71\right)$

\begin{tabular}{lrcr}
\hline Variable & Parameter estimate & Standard error & $p$ Value \\
\hline Intercept & -398.51 & 119.96 & 0.0050 \\
On.Ty & 12.03 & 2.89 & 0.0009 \\
Dark.On.Ar & -1.55 & 0.45 & 0.0041 \\
Alt.On.Ar & -3.60 & 0.64 & $<0.0001$ \\
Bright.On.Ar & 9.79 & 1.56 & $<0.0001$ \\
Dark.On.Dm & 1.56 & 0.27 & $<0.0001$ \\
Alt.On.Dm & 2.58 & 0.89 & 0.0114 \\
Bright.On.Dm & -1.82 & 0.34 & 0.0001 \\
Porosity & 12.28 & 1.72 & 0.0001 \\
Failure mode & -13.20 & 5.39 & 0.0283 \\
\hline
\end{tabular}

Numeric code for the osteon type (On.Ty), are: Hooped (1), dark field (2), alternating (3), bright field (4). Failure mode is either 3 for a interlamellar fracture or 4 for a cement line fracture.

However, the difference between the cement line and interlamellar interfaces may be the collagen itself. The interlamellar interface for human tissue has been described as containing loosely bound collagen between densely packed collagen (Marotti, 1993; Marotti et al., 1995) rather than a simple demarcation. SEM analyses revealed the presence of interlamellar collagen in equine osteons, revealing some of the complexity of the osteon structure (Fig. 6).

The lack of collagen fibers within the cement line may be more involved in energy dissipation via frictional sliding than in crack propagation resistance. Such fibers in the interface would resist friction sliding once catastrophic crack propagation completed (Fig. 6). This would agree with the observation that the sliding stress of the interlamellar interface is greater than the cement line (Table 6). The combination of these two physical findings may suggest a mechanism for overall bone fracture resistance by creating a weak, energy dissipative interface.

The differences in interfacial shear stress associated with proximodistal location may be attributed to the mechanical loading environment. These pushout data suggest that the highest values of maximum interfacial shear stress is in the proximal diaphysis while those in the mid to distal diaphyses are lower. Osteon spatial orientation is heavily influenced by magnitudes of torsion and bending moments (Braidotti et al., 1995). These influences may not only contribute to spatial orientation, but also to changes in the area fraction of osteons as well as changes in osteon interfacial properties resulting in decreased maximum interfacial shear stress within the mid to distal diaphyses. These differences may also be due to variation of elastic properties as noted earlier.

Regional differences in osteon shear strength has been confirmed. The regional differences in strength can best 
be explained by bone regional histomorphometry. There are also differences in interfacial strength associated with osteon type, best accounted for by collagen fiber orientation. These observations are in general agreement with the literature of fracture and fatigue of cortical bone. These results strongly support the idea that bone is a "smart" structure, adapting to the loading environment to create a mechanically optimized tissue, and the general idea of Wolff's Law.

\section{Acknowledgements}

This research was supported by NIH Grant RO1 DE13579. Instrumentation was provided by the US. Army Institute of Surgical Research, San Antonio, TX. We also thank Dr. Sue Stover at the California Center for Equine Health and UC Davis for the donation of the equine metacarpal bone tissue. We are grateful to Dr. R.B. Martin and Dr. J.C. Gibeling for their helpful discussions and editorial comments, and to Dr. C.M. Les at Henry Ford Hospital for statistical advice.

\section{References}

Alto, A., Pope, M.H., 1979. On the fracture toughness of equine metacarpi. Journal of Biomechanics 12, 415-421.

Ascenzi, A., Ascenzi, M.G., Benvenuti, A., Mango, F., 1997. Pinching in longitudinal and alternate osteons during cyclic loading. Journal of Biomechanics 30, 689-695.

Ascenzi, A., Benvenuti, A., 1986. Orientation of collagen fibers at the boundary between two successive osteonic lamellae and its mechanical interpretation. Journal of Biomechanics 19, 455-463.

Ascenzi, A., Bonucci, E., 1967. The tensile properties of single osteons. Anatomical Records 158, 375-386.

Ascenzi, A., Bonucci, E., 1968. The compressive properties of single osteons. Anatomical Records 161, 377-391.

Ascenzi, A., Bonucci, E., 1972. The shearing properties of single osteons. Anatomical Records 172, 499-510.

Ascenzi, A., Bonucci, E., 1976. Mechanical similarities between alternate osteons and cross-ply laminates. Journal of Biomechanics 9, 65-71.

Ascenzi, M.G., Ascenzi, A., Benvenuti, A., Burghammer, M., Panzavolta, S., Bigi, A., 2003. Structural differences between "dark" and "bright" isolated human osteonic lamellae. Journal of Structural Biology 141, 22-33.

Behiri, J.C., Bonfield, W., Charalambides, B., 1987. Mechanisms of crack propagation in bone. In: Bergamann, G., Kobel, R., Rohlmann, A. (Eds.), Biomechanics: Basic and Applied Research. Martinus Nijhoff Publishers, Dordrecht, The Netherlands.

Bell, K.L., Loveridge, N., Power, J., Garrahan, N., Meggitt, B.F., Reeve, J., 1999. Regional differences in cortical porosity in the fractured femoral neck. Bone 24, 57-64.

Bonfield, W., 1987. Advances in the fracture mechanics of cortical bone. Journal of Biomechanics 20, 1071-1081.

Bonfield, W., Behiri, J.C., 1989. Fracture toughness of natural composites with reference to bone. In: Friedrich, K. (Ed.), Applications of fracture mechanics to composite materials. Elsevier, New York, pp. 615-635.
Braidotti, P., Branca, F.P., Sciubba, E., Stagni, L., 1995. An elastic compound tube model for a single osteon. Journal of Biomechanics 28, 439-444.

Bright, J.D., Shetty, D.K., Griffin, C.W., Limaye, S.Y., 1989. Interfacial bonding and friction in silicon carbide (filament)reinforced ceramic-and glass-matrix composites. Journal of the American Ceramic Society 72, 1891-1898.

Burr, D.B., Schaffler, M.B., Frederickson, R.G., 1988. Composition of the cement line and its possible mechanical role as a local interface in human compact bone. Journal of Biomechanics 21, 939-945.

Cooke, F.W., Zeidman, H., Scheifele, S.J., 1973. The fracture mechanics of bone - another look at composite modeling. Journal of Biomedical Materials Research 7, 383-399.

Corondan, G., Haworth, W.L., 1986. A fractographic study of human long bone. Journal of Biomechanics 19, 207-218.

Dong, X.N., Guo, X.E., 2000. Is the cement line a weak interface? In: Proceedings of the 46th Annual Meeting of the Orthopaedic Research Society, Orlando, FL.

Dong, X.N., Guo, X.E., 2001. Extracting intrinsic debonding strength of cement lines from osteon pushout experiments. In: Proceedings of the 47th Annual Meeting of the Orthopaedic Research Society, San Francisco, CA.

Frost, H.M., Roth, H., Villanueva, A.R., 1961. Physical characteristics of bone-Part III. A semi-micro measurement of unit shear stress. Henry Ford Hospital Medical Journals 9, 156-162.

Gibson, V.A., Stover, S.M., Martin, R.B., Gibeling, J.C., Willits, N.H., Gustafson, M.B., Griffin, L.V., 1995. Fatigue behavior of the equine third metacarpus: mechanical property analysis. Journal of Orthopaedic Research 13, 861-868.

Griffin, L.V., Gibeling, J.C., Martin, R.B., Gibson, V.A., Stover, S.M., 1997. Model of flexural fatigue damage accumulation for cortical bone. Journal of Orthopaedic Research 15, 607-614.

Guo, X.E., Liang, L.C., Goldstein, S.A., 1998. Micromechanics of osteonal cortical bone fracture. Journal of Biomechanical Engineering 120, 112-117.

Gustafson, M.B., Martin, R.B., Gibson, V., Storms, D.H., Stover, S.M., Gibeling, J., Griffin, L., 1996. Calcium buffering is required to maintain bone stiffness in saline solution. Journal of Biomechanics 29, 1191-1194.

Hiller, L.P., Stover, S.M., Gibson, V.A., Gibeling, J.C., Prater, C.S., Hazelwood, S.J., Yeh, O.C., Martin, R.B., 2003a. Osteon pullout in the equine third metacarpal bone: effects of ex vivo fatigue. Journal of Orthopaedic Research in press.

Hiller, L.P., Stover, S.M., Gibson, V.A., Gibeling, J.C., Prater, C.S., Hazelwood, S.J., Yeh, O.C., Martin, R.B., 2003b. Osteon pullout in the equine third metacarpal bone: effects of ex vivo fatigue. Journal of Orthopaedic Research 21, 481-488.

Hogan, H.A., 1992. Micromechanics modeling of Haversian cortical bone properties. Journal of Biomechanics 25, 549-556.

Katz, J.L., Yoon, H.S., Lipson, S., Maharidge, R., Meunier, A., Christel, P., 1984. The effects of remodeling on the elastic properties of bone. Calcified Tissue International 36 (Suppl. 1), S31-S36.

Lawrence, P., 1972. Some theoretical considerations of fiber pullout fram an elastic matrix. Journal of Materials Science 1, 1-6.

Les, C.M., Keyak, J.H., Stover, S.M., Taylor, K.T., Kaneps, A.J., 1994. Estimation of material properties in the equine metacarpus with use of quantitative computed tomography. Journal of Orthopaedic Research 12, 822-833.

Les, C.M., Stover, S.M., Keyak, J.H., Taylor, K.T., Willits, N.H., 1997. The distribution of material properties in the equine third metacarpal bone serves to enhance sagittal bending. Journal of Biomechanics 30, 355-361.

Malik, C.L., Stover, S.M., Martin, R.B., Gibeling, J.C., 2003. Equine cortical bone exhibits rising R-curve fracture mechanics. Journal of Biomechanics 36, 191-198. 
Marotti, G., 1993. A new theory of bone lamellation. Calcified Tissue International 53 (Suppl 1), S47-55 discussion S56.

Marotti, G., Muglia, M.A., Palumbo, C., 1995. Collagen texture and osteocyte distribution in lamellar bone. Italian Journal of Anatomy and Embryology 100 (Suppl. 1), 95-102.

Martin, R.B., Gibson, V.A., Stover, S.M., Gibeling, J.C., Griffin, L.V., 1996a. Osteonal structure in the equine third metacarpus. Bone 19, $165-171$.

Martin, R.B., Stover, S.M., Gibson, V.A., Gibeling, J.C., Griffin, L.V., 1996b. In vitro fatigue behavior of the equine third metacarpus: remodeling and microcrack damage analysis. Journal of Orthopaedic Research 14, 794-801.

Moyle, D.D., Bowden, R.W., 1984. Fracture of human femoral bone. Journal of Biomechanics 17, 203-213.

Moyle, D.D., Welborn 3rd., J.W., Cooke, F.W., 1978. Work to fracture of canine femoral bone. Journal of Biomechanics 11, 435-440.

Norman, T.L., Nivargikar, S.V., Burr, D.B., 1996. Resistance to crack growth in human cortical bone is greater in shear than in tension. Journal of Biomechanics 29, 1023-1031.
Norman, T.L., Wang, Z., 1997. Microdamage of human cortical bone: incidence and morphology in long bones. Bone 20, 375-379.

Norman, T.L., Yeni, Y.N., Brown, C.U., Wang, Z., 1998. Influence of microdamage on fracture toughness of the human femur and tibia. Bone 23, 303-306

Piekarski, K., 1970. Fracture of bone. Journal of Applied Physics 41, 215-223.

Pope, M.H., Outwater, J.O., 1972. The fracture characteristic of bone substance. Journal of Biomechanics 5, 457-465.

Stover, S.M., Gibson, V.A., Martin, R.B., Gibeling, J.C., Griffin, L.V., 1995. Osteonal pullout increases fatigue life of cortical bone. In: Proceedings of the 41st Annual Meeting of the Orthopaedic Research Society, New Orleans, LA.

Wells, J.K., Beaumont, P.W.R., 1985. Debonding and pullout processes in fiberous composites. Journal of Materials Science 20, $1275-1284$.

Yeni, Y.N., Fyhrie, D.P., 2002. Fatigue damage-fracture mechanics interaction in cortical bone. Bone 30, 509-514. 